American Journal of Animal and Veterinary Sciences 5 (1): 60-64, 2010

ISSN 1557-4555

(C) 2010 Science Publications

\title{
Impact of Dietary Fat Type and Amount on Growth Performance and Serum Cholesterol in Rabbits
}

\author{
A. Alhaidary, H.E. Mohamed and A.C. Beynen \\ Department of Animal Production, College of Food and Agricultural Sciences, \\ King Saud University, Riyadh, Kingdom of Saudi Arabia
}

\begin{abstract}
Problem statement: Literature data on the effect of dietary fat on growth performance in rabbits are inconclusive. For commercial rabbit production it is relevant to know to what extent dietary fat level and type can be manipulated. In the present study serum cholesterol was also analyzed because its relation to the amount and type of dietary fat was not known for rabbits. Approach: Young growing rabbits were fed diets containing one of four different levels (5.2-41.8 energy \%) of either coconut fat or corn oil. Fat was added to the diets at the expense of an isoenergetic amount of corn starch and dextrose in a 1:1 ratio. The diets were in pelleted form and supplied ad libitum. Results: Increasing fat intakes in the form of either coconut fat or corn oil enhanced weight gain and improved feed efficiency. The effect of coconut fat was maximal at 20.9 energy $\%(9.9 \%$, w/w) and the greatest effect of corn oil was seen at an inclusion level of 41.8 energy $\%(20.2 \%$, w/w). As would be expected, replacement of dietary corn oil by coconut fat significantly decreased serum cholesterol concentrations. The cholesterol-lowering effect of corn oil versus coconut fat increased markedly with higher dietary inclusion levels of fat. Conclusion: The addition of fat to the diet improved growth performance. It is suggested to find out whether the present observations can be applied in the formulation of diets for fryer rabbits. The new observation for rabbits is that the hypocholesterolemic response to corn oil increased with higher intake levels.
\end{abstract}

Key words: Rabbits, coconut fat, corn oil, saturated fatty acids, polyunsaturated fatty acids, growth performance, cholesterol

\section{INTRODUCTION}

The requirement of dietary fat by rabbits has been set at $2 \%(\mathrm{w} / \mathrm{w})$ of a diet containing $90 \%(\mathrm{w} / \mathrm{w})$ of dry matter (National Research Council, 1977). Since plant foodstuffs form the basis of rabbit diets, the recommended amount of dietary fat will provide sufficient essential fatty acids and it is likely that the absorption of fat soluble vitamins will be adequate. Fats represent a concentrated form of energy and an increase in fat will increase energy density of the diet. If an increase in dietary level does not negatively affect feed intake, it should enhance growth performance of rabbits, but an overview of six published studies showed controversial results (Beynen, 1988a). The discrepancies between the outcome of the various studies most likely is explained by different background compositions of the experimental diets, the use of different types of fat and the addition of extra fat to the diet at the expense of an equal weight of carbohydrates rather than an isoenergetic amount (Beynen, 1988a).

The isoenergetic replacement of carbohydrates by corn oil has been found to improve growth in rabbits irrespective of whether the animals were fed restricted, isoenergetic amounts of feed (Van Manen et al., 1989) or had free access to feed (Beynen, 1988b). After the 1988 review (Beynen, 1988a), seven more studies on fat intake and growth performance by rabbits have been published. In four studies, only the effect of the type of fat was studied (Kelley et al., 1988; Abdelhamid, 1989; Fernández and Fraga, 1996; Cobos et al., 1993) and in three studies there were multiple dietary variables in addition to fat type and level (Santomá et al., 1987; Egbo et al., 2004; Chen and Li, 2008). Maertens (1998) stated in a literature review that the addition of fat to the diet of fryer rabbits may not alter growth rates, but may favorably influence feed efficiency. This statement is based on studies with inappropriate design (Beynen, 1988a), whereas reports showing

Corresponding Author: Ahmed Alhaidary, Department of Animal Production, College of Food and Agricultural Sciences, King Saud University, P.O. Box 2460, Riyadh 11451, Kingdom of Saudi Arabia Tel: +966 14678475 Fax: +966 14678474 
enhanced growth after fat addition to the diet (Beynen, 1988b; Van Manen et al., 1989) were not reviewed (Maertens, 1998). For commercial rabbit production it still is relevant to address the question to what extent dietary fat level and type influence growth performance when feed is freely available. Thus, we communicate a study with young growing rabbits fed ad libitum on diets containing different levels of either coconut fat or corn oil and we determined growth and feed intake.

The type of fat in the diet is the major determinant of serum cholesterol concentrations in humans (Kritchevsky, 2001). Replacement of saturated by omega-6 polyunsaturated fatty acids lowers serum cholesterol and formulas have been developed to predict the quantitative effects (Mensink et al., 2003). In spite of the vast amount of quantitative data, the mechanism by which omega- 6 polyunsaturated fatty acids lower serum cholesterol remains obscure. The rabbit is often used in studies on cholesterol metabolism and in qualitative terms, the effect of dietary fat type on serum cholesterol resembles that in humans (Beynen and Katan, 1989; Kritchevsky, 1991). However, the effect of dietary fat type and level in a dose-response fashion has not been studied so that the interactions between type and level are still poorly understood (Kritchevsky, 2001). The present study on growth performance of rabbits offered the opportunity to study the effect of dietary fat amount and type on serum cholesterol concentrations. Thus, in addition to the data on growth performance, we also report the serum and liver cholesterol concentrations found in the rabbits.

\section{MATERIALS AND METHODS}

Random-bred, male rabbits of the New Zealand strain were used. The rabbits were housed individually as described earlier (Beynen et al., 1986, Beynen, 1988b). Food and water were provided ad libitum.

On arrival in the animal house, the rabbits, which were aged about 6 weeks, were maintained on commercial rabbit pellets for two weeks. Subsequently, on the basis of their body weights, the rabbits were allocated to the experimental diets given in Table 1 . Each dietary group consisted of 8 animals. The diets contained four levels of either coconut fat or corn oil as fat source. Extra fat was added to the low-fat diet at the expense of an isoenergetic amount of corn starch and dextrose in a 1:1 ratio. The diets were in pelleted form.

The experimental period lasted 56 days. Body weights and feed intake were measured. One week before the beginning and at the end of the experiment, blood samples were taken from the lateral ear vein for cholesterol determination. At the end of the experiment,
Table 1: Composition of the experimental diets

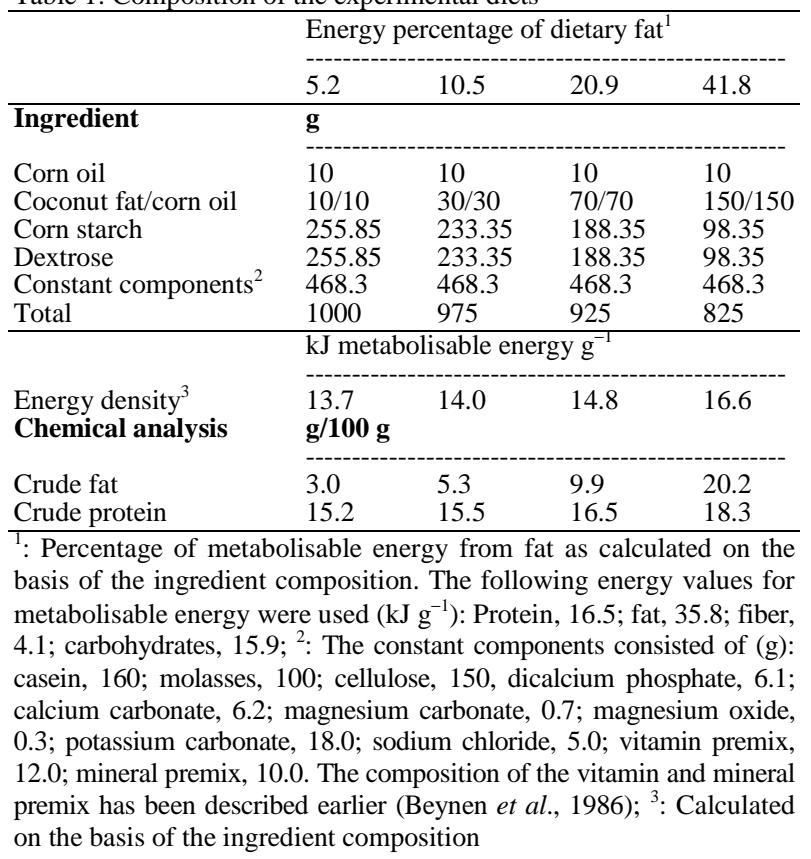

the rabbits were killed by cervical dislocation and cutting the carotid arteries and jugular veins. Livers were removed and weighed. Serum and liver cholesterol were analyzed as described (Yuangklang et al., 2005).

The data were subjected to two-way ANOVA to identify statistically significant effects of fat type, fat level and the interaction between type and level. The level of statistical significance was pre-set at $p<0.05$.

\section{RESULTS}

Table 2 summarizes the observations on growth performance. Final body weights were systematically lower in the rabbits fed the diets containing coconut fat than in their counterparts fed the diets with corn oil. Increasing the level of corn oil in the diet produced a dose-dependent increase in final body weight. Between 5.2 and 20.9 energy \% coconut fat in the diet, an increase in coconut fat intake raised final body weight, but there was a fall with the highest level.

The diet effects on final body weight were paralleled by those on feed intake. Increasing levels of corn oil or coconut fat in the diet raised feed intake, but only for coconut fat the highest inclusion level reduced feed intake substantially. The addition of increasing amounts of corn oil or coconut fat to the diet generally improved feed conversion, except for the highest level of coconut fat which lowered feed efficiency to a value similar to those seen on the diets with lowest fat content. The energy intake per unit of weight gain was increased for the diet with the highest level of coconut fat, but for the other three diets containing coconut fat it was similar. 
American J. Animal \& Vet. Sci., 5 (1): 60-64, 2010

Table 2: Body weights, feed intake and feed conversion in rabbits fed the experimental diets

\begin{tabular}{|c|c|c|c|c|c|}
\hline \multirow[b]{2}{*}{ Type of fat } & \multicolumn{4}{|c|}{ Energy percentage of dietary fat } & \multirow[b]{2}{*}{ Significance } \\
\hline & 5.2 & 10.5 & 20.9 & 41.8 & \\
\hline \multicolumn{6}{|c|}{ Body weight, kg } \\
\hline Coconut & $1.69 \pm 0.05$ & $1.66 \pm 0.05$ & $1.72 \pm 0.05$ & $1.69 \pm 0.04$ & \\
\hline Corn & $1.68 \pm 0.06$ & $1.68 \pm 0.05$ & $1.71 \pm 0.05$ & $1.71 \pm 0.05$ & \\
\hline \multicolumn{6}{|l|}{ Day 56} \\
\hline Coconut & $2.92 \pm 0.11$ & $3.15 \pm 0.10$ & $3.28 \pm 0.09$ & $2.73 \pm 0.16$ & A, T, AxT \\
\hline Corn & $3.01 \pm 0.12$ & $3.27 \pm 0.11$ & $3.36 \pm 0.13$ & $3.85 \pm 0.12$ & \\
\hline \multicolumn{6}{|c|}{ Feed intake, $\mathrm{g} \mathrm{day}^{-1}$} \\
\hline Coconut & $85.1 \pm 4.9$ & $99.4 \pm 4.4$ & $100.0 \pm 3.7$ & $72.5 \pm 4.0$ & $\mathrm{~A}, \mathrm{~T}, \mathrm{AxT}$ \\
\hline Corn & $94.6 \pm 5.6$ & $103.6 \pm 5.5$ & $107.5 \pm 6.1$ & $116.1 \pm 4.3$ & \\
\hline \multicolumn{6}{|c|}{ Feed conversion, $\mathrm{g}$ feed $\mathrm{g}^{-1}$ gain } \\
\hline Coconut & $3.88 \pm 0.08$ & $3.73 \pm 0.07$ & $3.59 \pm 0.06$ & $3.92 \pm 0.13$ & A, AxT \\
\hline Corn & $3.99 \pm 0.11$ & $3.65 \pm 0.14$ & $3.68 \pm 0.18$ & $3.06 \pm 0.12$ & \\
\hline \multicolumn{6}{|c|}{ Energy conversion, $\mathbf{k J ~ g}^{-1}$ gain } \\
\hline Coconut & $53.2 \pm 1.10$ & $52.2 \pm 0.98$ & $53.2 \pm 0.89$ & $65.1 \pm 2.16$ & $\mathrm{~T}, \mathrm{AxT}$ \\
\hline Corn & $54.7 \pm 1.51$ & $60.0 \pm 1.96$ & $54.0 \pm 2.66$ & $50.0 \pm 1.99$ & \\
\hline
\end{tabular}

Results are expressed as means \pm SE for 8 rabbits per dietary group, except for the rabbits fed the 20.9 energy percentage corn-oil diet, which consisted of 7 animals. ${ }^{1}$ : Significance was calculated by analysis of variance. A: Effect of amount of fat; T: Effect of type of fat; AxT: Effect of interaction; NS: No Significant effect of amount and type of fat

Table 3: Serum and liver cholesterol concentrations in rabbits fed the experimental diets

\begin{tabular}{|c|c|c|c|c|c|}
\hline \multirow[b]{2}{*}{ Type of fat } & \multicolumn{4}{|c|}{ Energy percentage of dietary fat } & \multirow[b]{2}{*}{ Significance } \\
\hline & 5.2 & 10.5 & 20.9 & 41.8 & \\
\hline \multicolumn{6}{|c|}{ Serum cholesterol, $\mathrm{mmol} \mathrm{L}^{-1}$} \\
\hline \multicolumn{6}{|c|}{ Day-7 } \\
\hline Coconut & $1.54 \pm 0.10$ & $1.51 \pm 0.08$ & $1.57 \pm 0.10$ & $1.52 \pm 0.11$ & \\
\hline Corn & $1.49 \pm 0.11$ & $1.44 \pm 0.09$ & $1.43 \pm 0.14$ & $1.53 \pm 0.17$ & \\
\hline \multicolumn{6}{|l|}{ Day 56} \\
\hline Coconut & $6.85 \pm 1.16$ & $6.50 \pm 1.20$ & $8.54 \pm 1.29$ & $12.34 \pm 2.67$ & $\mathrm{~T}, \mathrm{AxT}$ \\
\hline Corn & $5.74 \pm 1.29$ & $5.37 \pm 0.74$ & $3.48 \pm 0.54$ & $2.75 \pm 0.45$ & \\
\hline \multicolumn{6}{|c|}{ Liver weight $\mathrm{g}$} \\
\hline Coconut & $100.5 \pm 4.7$ & $119.7 \pm 5.7$ & $121.5 \pm 5.2$ & $80.1 \pm 10.4$ & AxT \\
\hline Corn & $118.3 \pm 9.2$ & $116.2 \pm 9.1$ & $86.9 \pm 4.5$ & $114.5 \pm 11.4$ & \\
\hline \multicolumn{6}{|c|}{ Liver cholesterol, $\mu \mathrm{mol} \mathrm{\textrm {g } ^ { - 1 }}$} \\
\hline Coconut & $10.01 \pm 0.59$ & $9.27 \pm 0.90$ & $9.06 \pm 0.77$ & $10.79 \pm 1.48$ & NS \\
\hline Corn & $7.79 \pm 0.64$ & $8.93 \pm 0.91$ & $8.37 \pm 0.77$ & $9.41 \pm 1.35$ & \\
\hline
\end{tabular}

Results are expressed as means \pm SE for 8 rabbits per dietary group, except for the rabbits fed the 20.9 energy percentage corn-oil diet, which consisted of 7 animals. ${ }^{1}$ : Significance was calculated by analysis of variance. A: Effect of amount of fat; T: Effect of type of fat; AxT: Effect of interaction; NS: No Significant effect of amount and type of fat

For the diets with corn oil, energy conversion was most favorable at the highest inclusion level.

There were clear effects of dietary fat type and amount on serum cholesterol concentrations (Table 3). The feeding of corn oil instead of coconut fat at identical inclusion levels consistently reduced cholesterol concentrations. Increasing dietary levels of coconut fat raised cholesterol concentrations, whereas increasing levels of corn oil caused a dose-dependent decrease. Liver cholesterol concentrations were not affected by dietary fat type and amount.

\section{DISCUSSION}

In an earlier study, rabbits were fed different dietary levels of corn oil in diets with identical composition as those used in the present study, but they were fed restricted amounts of feed to equalize energy intake (Van Manen et al., 1989). In that study it was found that increased corn oil intake raised weight gain in a dose-dependent fashion up to 20.9 energy $\%$ in the diet. Because the rabbits were fed isoenergetic amounts of feed, it would appear that growth is more efficient with dietary energy in the form of fat than carbohydrates. Alternatively, it could be suggested that high fat intakes change carcass composition towards a higher protein content and thus higher water content so that body weight becomes increased. However, there is no evidence for an effect of increased fat intake on carcass composition (Beynen et al., 1989; Cobos et al., 1993; Fernández and Fraga, 1996). The present study, which was carried out under ad libitum conditions, also shows 
that increasing dietary corn oil level up to 20.9 energy $\%$ in the diet increases final body weight, but even up to 41.8 energy \% weight gain was raised. Moreover, feed intake was increased in a dose-dependent fashion, but feed conversion became more favorable. Thus, high corn oil intakes most likely had promoted the efficiency of feed utilization. This effect might be related to the recent observation that a high fat intake by rabbits stimulates insulin secretion (Zhao et al., 2008).

This study shows a clear effect of the type of fat on growth performance. Dietary coconut fat raised final body weight up to an inclusion level of 20.9 energy \%, but at the 41.8 energy \% level weight gain had fallen. Feed intake showed the same pattern. Increasing intakes of coconut fat improved feed efficiency, but at the highest level feed efficiency worsened. Possibly, the high amount of coconut fat had a negative impact on palatability. The lower feed intake had increased the dietary fraction of energy used for maintenance so that the feed efficiency became less favorable. Previous studies have also shown an effect of the type of fat on growth performance. Abdelhamid (1989) found that beef tallow enhanced feed intake and growth when compared with cotton seed oil or hydrogenated palm oil. Lard versus soybean oil has been reported to lower feed intake and improve feed efficiency (Chen and Li, 2008). Likewise, butter instead of groundnut oil lowered feed intake and improved feed efficiency (Egbo et al., 2004). Kelley et al. (1988) observed greater weight gain on diets containing either safflower oil or linseed oil when compared with hydrogenated soybean oil or menhaden oil. In other studies there was no effect of fat type on growth performance (Fernández and Fraga, 1996; Santomá et al., 1987). Thus, taken all data together the issue of dietary fat type and growth performance in rabbits does not yet form a clear picture.

Feeding of the low-fat, experimental diets was associated with a marked increase in serum cholesterol (Table 3). This increase is explained by the hypercholesterolemic activity of the casein component in the experimental diets (Beynen et al., 1983). Coconut fat is rich in saturated fatty acids, lauric, myristic and palmitic acid together comprising about $70 \%$ of total fatty acids. Corn oil, on the other hand, is rich in the polyunsaturated omega- 6 fatty acid, linoleic acid, the amount being about $53 \%$ of total fatty acids. The levels of palmitic and oleic acid in corn oil are about 10 and $25 \%$. It is well-known that oils rich in linoleic acid lower serum cholesterol concentrations in rabbits, when compared with saturated fatty acids (Kritchevsky, 1991). The present data confirm that replacement of dietary corn oil by coconut fat significantly decreases serum cholesterol concentrations (Beynen and West,
1981). The new observation for rabbits is that the cholesterol-lowering effect of corn oil versus coconut fat is greater at higher dietary inclusion levels. In other words, there is a dose-response relationship between dietary fat level and serum cholesterol. Extra coconut fat above 10.5 energy percentage in the diet raised serum cholesterol, whereas extra corn oil had a lowering effect. In an extensive meta-analysis of studies in humans, Mensink et al. (2003) computed that serum total cholesterol will increase by $0.036 \mathrm{mmol} \mathrm{L}^{-1}$ when carbohydrates constituting $1 \%$ of dietary energy are replaced by saturated fatty acids, whereas with replacement by monounsaturated or polyunsaturated fatty acids there is a decrease by 0.006 and $0.021 \mathrm{mmol} \mathrm{L}^{-1}$, respectively. In the rabbits, an increase in coconut fat and corn oil from 5.2-41.8 energy $\%$ increased and decreased serum cholesterol by 5.49 and $2.99 \mathrm{mmol} \mathrm{L}^{-1}$, respectively. When assuming that coconut fat and corn oil contain $50 \%$ of saturated or polyunsaturated fatty acids as the only cholesteroldetermining fatty acids, the application of the formula of Mensink et al. (2003) would predict an increase by $0.65 \mathrm{mmol} \mathrm{L}^{-1}$ after feeding coconut fat and a decrease by $0.38 \mathrm{mmol} \mathrm{L}^{-1}$ after feeding corn oil. At the fixed fat level of 41.8 energy $\%$, there is a replacement of saturated by polyunsaturated fatty acids which caused a fall in serum cholesterol by $9.59 \mathrm{mmol} \mathrm{L}^{-1}$. The predicted lowering in humans would be $1.03 \mathrm{mmol} \mathrm{L}^{-1}$. Thus, it appears that rabbits are extremely sensitive to the cholesterolemic effect of dietary fat type. In a qualitative sense, the rabbit may be a model to study effects of dietary fats on serum cholesterol metabolism, but in quantitative terms it is not.

\section{CONCLUSION}

In conclusion, this study, in which rabbits had free access to feed, has demonstrated that increasing fat intakes in the form of either coconut fat or corn oil enhanced weight gain and improved feed efficiency. The positive effect of corn oil has also been seen earlier under conditions of restricted, isoenergetic feeding (Van Manen et al., 1989). The effect of coconut fat was maximal at 20.9 energy $\%$ and the maximum effect of corn oil was seen at an inclusion level of 41.8 energy $\%$. In this study, semipurified diets were used. It would be important to see whether the present observations can be applied in practical diet formulation for fryer rabbits.

\section{REFERENCES}

Abdelhamid, A.M., 1989. Possibility of fat addition in the rabbit diets. Arch. Anim. Nutr., 39: 729-739. PMID: 2818194 
Beynen, A.C. and M.B. Katan, Impact of Dietary Cholesterol and Fatty Acids on Serum Lipids and Lipoproteins in Man. In: The Role of Fats in Human Nutrition, Vergroesen, A.J. and M.A. Crawford (Eds.). Academic Press, London. ISBN: 0127180516 1989, pp: 237-286.

Beynen, A.C., 1988a. Dietary fat level and growth performance by rabbits. J. Applied Rabbit Res. 11: 21-24.

Beynen, A.C., 1988b. Growth performance by rabbits fed diets containing various levels of corn oil. Proceedings of the 4th World Rabbit Congress, Section Nutrition and Pathology, (SNP'88), World Rabbit Science Association, Budapest, Hungary, pp: 230-234.

Beynen, A.C., D.G. van Manen and M.W.A. Verstegen, 1989. Dietary fat level and carcass quality of rabbits. J. Applied Rabbit Res., 12: 266-267.

Beynen, A.C. and C.E. West, 1981. The distribution of cholesterol between lipoprotein fractions of serum from rabbits fed semipurified diets containing casein and either coconut oil or corn oil. J. Anim. Physiol. Anim. Nutr., 46: 233-239. PMID: 7342549

Beynen, A.C., C.E. West, L.F.M. van Zutphen and M.B. Katan, 1986. Relation between the responses of serum cholesterol to dietary cholesterol and to the type of fat in random-bred rabbits. Nutr. Rep. Int., 33: 71-78.

Beynen, A.C., E.N.W. Winnubst and C.E. West, 1983. The effect of replacement of dietary soybean protein by casein on the fecal excretion of neutral steroids in rabbits. J. Anim. Physiol. Anim. Nutr., 49: 43-49. PMID: 6681922

Chen, P. and F.C. Li, 2008. Effect of dietary fat addition on growth performance, nutrient digestion and caecum fermentation in 2-3 months old meat rabbits. Proceedings of the 9th World Rabbit Congress, Section Nutrition and Digestive Physiology, (SNDP'08), World Rabbit Science Association, Verona, Italy, pp: 589-593.

Cobos, A., M.I. Cambero, J.A. Ordóñez and L. de la Hoz, 1993: Effect of fat-enriched diets on rabbit meat fatty acid composition. J. Sci. Food Agric. 62: 83-86. DOI: $10.1002 /$ jsfa.2740620112

Egbo, M.L., T.A. Adegbola, E.O. Oyawoye and M.M. Abu Bakar, 2004. Effect of varying levels of and sources of dietary fat on growth performance and nutrient digestibility in rabbits. Pertanika J. Trop. Agric. Sci., 27: 65-71.
Fernández, C. and M.J. Fraga, 1996. The effect of dietary fat inclusion on growth, carcass characteristics and chemical composition of rabbits. J. Anim. Sci., 74: 2088-2094. PMID: 8880410

Kelley, D.S., G.J. Nelson, C.M. Serrato, P.C. Schmidt and L.B. Branch, 1988. Effects of type of dietary fat on indices of immune status of rabbits. J. Nutr., 118: 1376-1384. PMID: 3193254

Kritchevsky, D., 1991. Dietary fat and experimental atherosclerosis. Int. J. Tiss. React., 13: 59-65. PMID: 1955294

Kritchevsky, D., 2001. Diet and atherosclerosis. J. Nutr. Health Aging, 5: 155-159. PMID: 11458285

Maertens, L., 1998. Fats in rabbit nutrition: A review. World Rabbit Sci., 6: 341-348.

Mensink, R.P., P.L. Zock, A.D.M. Kester and M.B. Katan, 2003. Effects of dietary fatty acids and carbohydrates on the ratio of serum total to HDL cholesterol and on serum lipids and apolipoproteins: A meta-analysis of 60 controlled trials. Am. J. Clin. Nutr., 77: 1146-1155. PMID: 12716665

National Research Council, 1977. Nutrient Requirements of Rabbits. National Academy Press, Washington DC., ISBN: 0309026075, pp: 11-13.

Santomá, G., J.C. De Blas, R. Carabano and M.J. Fraga, 1987. The effect of different fats and their inclusion level in diets for growing rabbits. Anim. Prod., 45: 291-300.

Van Manen, D.G., M.W.A. Verstegen, G.W. Meijer and A.C. Beynen, 1989. Growth performance by rabbits after isoenergetic substitution of dietary fat for carbohydrates. Nutr. Rep. Int., 40: 443-450.

Yuangklang, C., Th. Wensing, A.G. Lemmens, S. Jittakhot and A.C. Beynen, 2005. Effect of sodium phytate supplementation on fat digestion and cholesterol metabolism in female rats. J. Anim. Physiol. Anim. Nutr., 89: 373-378. PMID: 16401188

Zhao, S., Y. Chu, C. Zhang, Y. Lin, K. Xu and P. Yang et al., 2008. Diet-induced central obesity and insulin resistance in rabbits. J. Anim. Physiol. Nutr., 92: 105-111. PMID: 18184386 